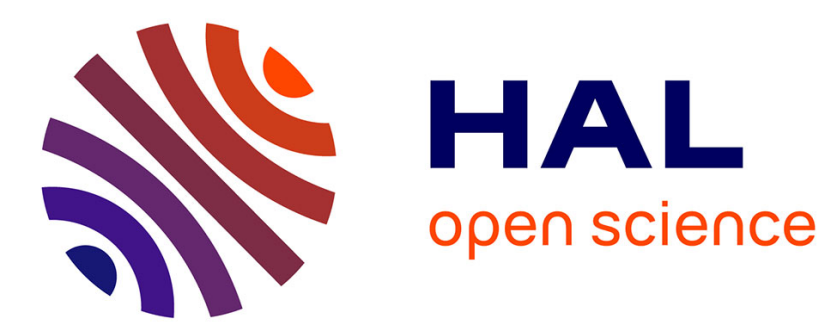

\title{
Comparing 2-D and 1-D/2-D modelling of Agly River bed change during a flood
}

S. Mezbache, André Paquier, M. Hasbaia

\section{To cite this version:}

S. Mezbache, André Paquier, M. Hasbaia. Comparing 2-D and 1-D/2-D modelling of Agly River bed change during a flood. River Flow 2020, Jul 2020, Delft, Netherlands. pp.704-710, 10.1201/b22619 . hal-03107142

\section{HAL Id: hal-03107142 \\ https://hal.science/hal-03107142}

Submitted on 12 Jan 2021

HAL is a multi-disciplinary open access archive for the deposit and dissemination of scientific research documents, whether they are published or not. The documents may come from teaching and research institutions in France or abroad, or from public or private research centers.
L'archive ouverte pluridisciplinaire HAL, est destinée au dépôt et à la diffusion de documents scientifiques de niveau recherche, publiés ou non, émanant des établissements d'enseignement et de recherche français ou étrangers, des laboratoires publics ou privés. 


\title{
Comparing 2-D and 1-D/2-D modelling of Agly River bed change during a flood
}

\author{
S. Mezbache \\ M'sila University, M'sila, Algeria
}

A. Paquier

INRAE, U.R. RiverLy, Villeurbanne, France

M. Hasbaia

M'sila University, M'sila, Algeria

\begin{abstract}
The authors discuss the use of a 1-D model or a 2-D model for the evolution of the bed between the levees while the spreading of water and sediment over the floodplains is simulated using a 2-D model. A 1-D model cannot represent the asymmetrical behaviour of the flow in the bends but makes easier the estimate of the variations of the sediment transport capacity along the river if the bed geometry is complex. For the case of the Agly river floods, results in terms of water elevation and bed evolution are compared for a simplified geometry of the bed. The two models (coupled 1-D/2-D or full 2-D) provide quite similar processes in the flood plain but different erosion rates of the main channel bed. Because differences of both results to observations are large, one cannot decide which model provides the more relevant results.
\end{abstract}

\section{INTRODUCTION}

The Agly river is located in the Southern part of France, in the Mediterranean region characterized by extreme flood events. The lower flood plain of Agly river is constituted of sediments brought from the upper catchment during centuries. Because of the intense use of the flood plain for agriculture, tourism and urban growth of Perpignan city, levees were built along the river and progressively reinforced, which did not prevent from occasional flooding during extreme floods. Many civil engineering structures were constructed along the river for various aims: flooding protection, dams, railway, roads, ... The flood plain materials are characterized by fine sediments while the bed materials are dominated by coarse sediments.

In this paper, the authors focus on the 13 kilometre long downstream reach, which is fitted out to the levees constructed in 1970 with a design discharge of $1300 \mathrm{~m}^{3} / \mathrm{s}$. Moreover, the simulated reach was extended by approximately $10 \mathrm{~km}$ upstream to eliminate any effect of the upstream boundary condition on the results.

The two more important floods after the levees building are studied. The first one was in 1992 with a return period of about 20 years, which means that the peak flow is close to the design flow discharge of the levees project; the second one was in 1999 corresponding to a 100-year return period and for which the levees are overtopped.

Inundations generated from river overflow are usually simulated by 1-D or 2-D numerical hydraulic models. The 1-D model is dedicated to the areas such as the river main channel in which the flow remains parallel to a hydraulic axis during the flood events; conversely, the 2-D model is limited to the areas such as flood plains in which the flow pattern evolves with time.

In this paper, throw numerical modelling of these two Agly floods, the main channel bed evolution is studied to find out the eroded and deposited zones. The authors compare also the calculated flooded zones with observations. In addition, a comparison between a coupled 1D/2D model and a full 2D model is carried out. The coupled 1D/2D model uses $1 \mathrm{D}$ modelling of the main channel between levees and 2D modelling for the flow and sediment transport in the floodplain; 
with this coupled method, one can reduce the calculation time avoiding more refined cells across the main channel.

\section{MATERIAL AND METHODS}

\subsection{Software}

\subsubsection{One dimensional model with sediment transport - RubarBE}

RubarBE software can simulate the flow and the bed evolution using 1D Saint Venant equations coupled with Exner equation (Exner 1925, El kadi \& Paquier 2009). The model solves these equations by a finite volume method with an explicit numerical scheme in which the time step is limited by the usual Courant-Friedrichs-Levy (CFL) condition (maximum Courant number selected: 0.9 here). The shear stress calculation is obtained throw the geometrical method called Merged Perpendicular Method (Khodashenas \& Paquier 1999). This latter calculation depends on the water depth so it permits more detailed modelling; especially in bends and where there are geometry variations (El kadi. \& Paquier 2009).

For Agly calculations, the assumption is that the local bed variation $d z$ is proportional to the local difference between effective and critical shear stresses with a 1.5 power. However, there are other possibilities proposed by the model. The section bed change is obtained from the difference between the upstream sediment discharge and the sediment transport capacity considering a lag distance. Several sediment layers are defined in each point of the geometry, each layer being characterized by three parameters that can evolve with time: a layer thickness, a mean diameter $d_{50}$ and a standard deviation $\sigma$. The evolution of the mean diameter and the standard deviation of the sediment carried out by the flow (sorting effect) is governed by an exponential law with specific lag distances (Camenen et al. 2018).

\subsubsection{Two dimensional model with sediment transport - Rubar20TS}

Rubar 20TS software (El Kadi et al. 2009) solves 2-D shallow water equations coupled to a sediment transport equation. It uses the same explicit Godunov scheme that the one in RubarBE and requires the same type of time step limitation (Courant number limited to 0.9 here). According to the complexity of the flow (Paquier 2019), the Riemann problem that calculates the flux across an edge can be replaced by a weir type equation (particularly relevant for a hydraulic structure). There is possibility to use quadrilateral or/and triangular meshes according to the geometry in order to adapt to field complex geometries. Similarly to RubarBE, several sediment layers are defined at each point of the geometry and time evolution of the sediment features depends of sediment balance and sorting lag distances. The rate of erosion and deposition at each point is calculated from the difference between the sediment discharge and the sediment transport capacity taking into account a lag distance.

\subsubsection{Coupled model}

The studied area is shared between a 1-D area and a 2-D area. Along the boundary between the two areas, coupling is performed at each time step. The 1D model and the 2D model are compiled as one single model, which permits quicker data transfers between the two models. The exchanged terms between the two models are the fluxes of mass (water and sediment) and momentum. Usually, the fluxes are calculated as solutions of a 1-D Riemann problem in the direction perpendicular to the boundary between the two models similarly to what is used in the 1-D and 2-D numerical schemes; then, hydraulic jump can be integrated as an ordinary calculation point even at the boundary between the two models (Paquier 2019).

\subsection{Building the model}

The data used to build the models were from (Serrat 2000) for sediment and the 1995 geometry of the main channel, from Water Authorities for the 1970 project geometry and 2000 geometries of the main channel, the flood plain geometry and the flow discharge hydrographs while the limits of the flooded areas were obtained from aerial photos. 
For computation, the initial geometry for the main channel was the 1970 project geometry simplified to 8 points cross sections in order to have exactly the same geometry in 1-D and 2-D models.

Sediment layers are represented with mean diameter $d_{50}=2 \mathrm{~mm}$, standard deviation $\sigma=10$ and not dimensional critical shear stress 0.047 . To be able to represent the variations of sediments during the flood events, four erodible layers, the thickness of each one is $1 \mathrm{~m}$, were set in the model. The space step is $100 \mathrm{~m}$ except where constructions obliged to reduce it. The lag distance that is the distance in which the transport reaches its capacity is fixed at 200 meters while the lag distance for sediment sorting is fixed at 1000 meters (Camenen et al. 2018). The presented results come from sediment transport capacity calculated by Meyer-Peter \& Müller (1948) equation using the total shear stress (because using a reduced shear stress does not provide significant erosion of the main channel bed).

\section{RESULTS}

\subsection{Main channel evolution}

For the two floods, Figures 1-2 show good agreement between the calculated longitudinal profile of maximum free water surface profile using one or the other model and the measured one. However, the 2-D model seems to underestimate the peak water elevation in the downstream part of the reach although the Strickler coefficients used for bed friction are the same ones and were selected on the basis of a 2-D calculation with fixed bed.

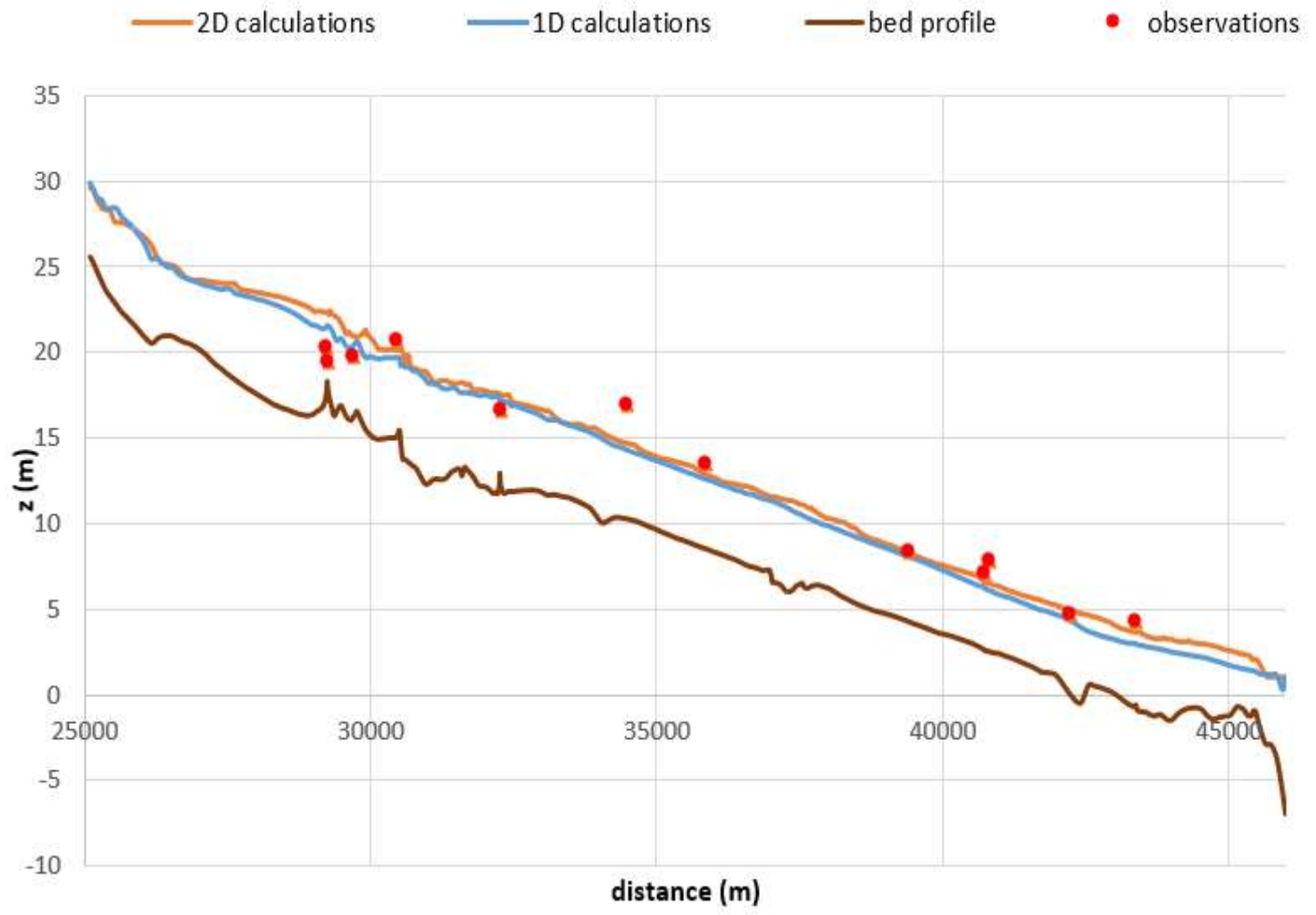

Figure 1. Comparison between measured and calculated longitudinal profile of peak water surface during the 1992 flood. 


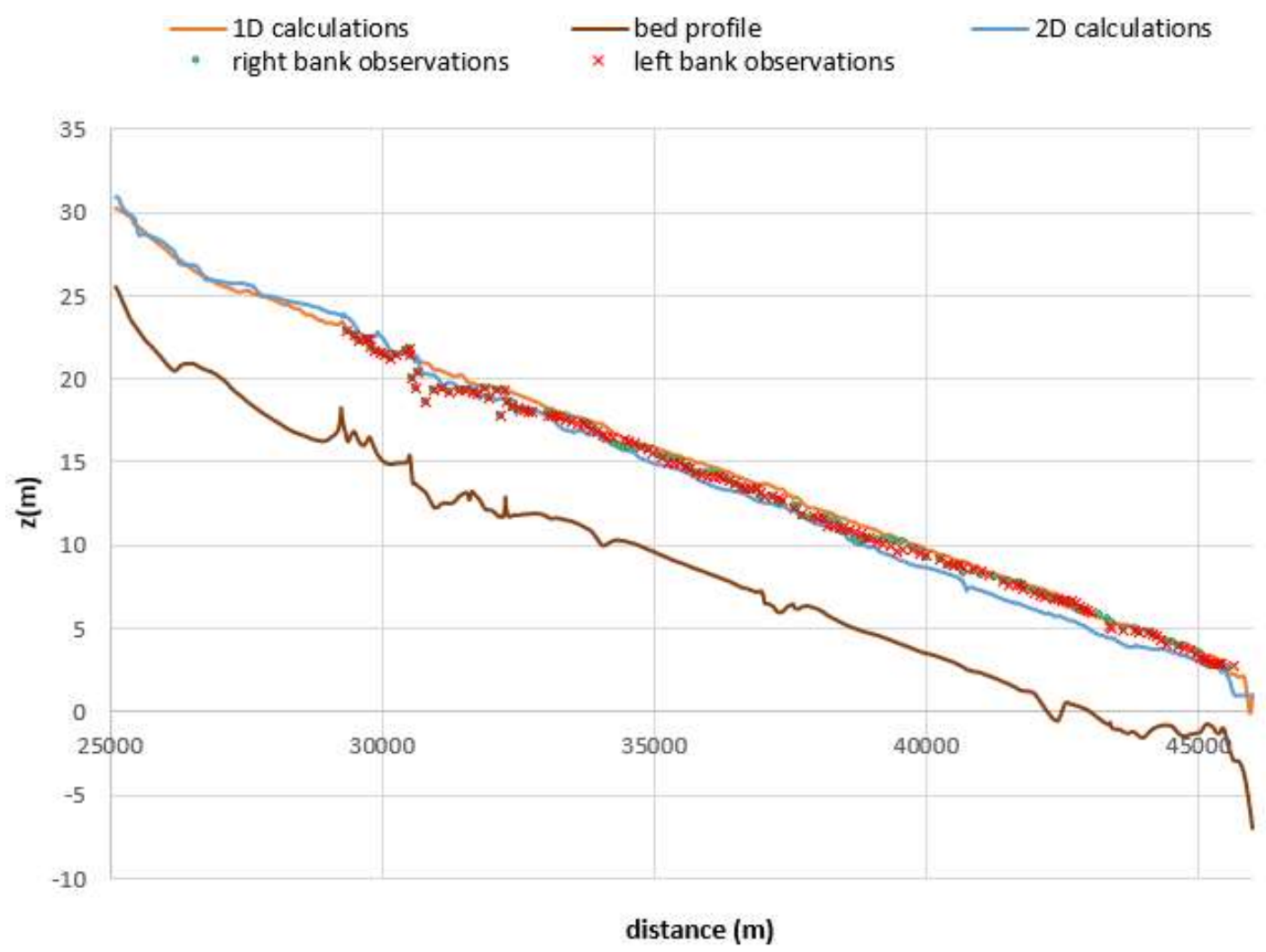

Figure 2. Comparison between calculated longitudinal profile of peak water surface during the 1999 flood and measured ones at the right and the left banks.

For the 2-D model, the bed during the 1992 and 1999 floods (Fig. 3) tends to an erosion in the most part of the longitudinal profile of the bed between levees like what is deduced from the comparison of geometries measured in 1995 and 2000 and the 1970 project geometry. For the coupled model, erosion alternates with deposition but represents the actual streamwise variations of the erosion or deposition depths in a better way. On Figure 3, note that calculation starts from 1970 project geometry and considers one flood (either 1992 or 1999) while observations considers changes over two periods 1970- 1995 (during which the main flood is the one of 1992) and 19952000 (during which the main flood is the one of 1999).

\subsection{Flood extent and floodplain deposits}

For the 1992 flood, the inundations are seldom as expected because the peak flow discharge corresponds to the design flow of the levees project. The calculated inundated area for the 1999 flood with 2-D or coupled 1-D/2-D models shows good agreement with the delimitation from the aerial photos in red in Figures 4-5. But the 2-D model (that was calibrated on observations) inundates more upstream than the coupled model, may be because the erosion of the main channel is lower at the locations in which overflow occurs. The area flooded through a breach in the levee is represented in a correct way if the breaching model (used in both models) provides enough erosion for a correct development of the breach. 


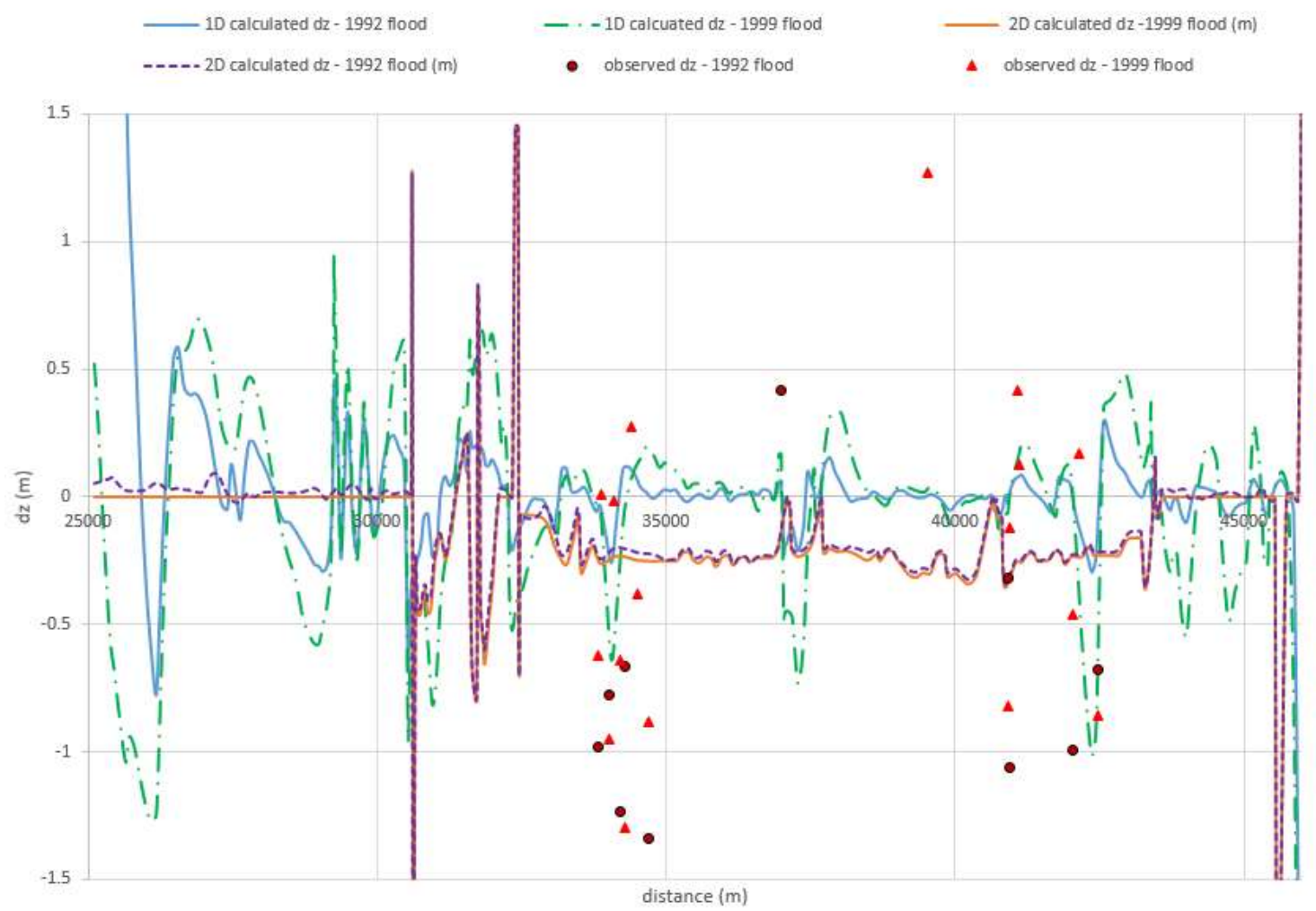

Figure 3. Calculated bed evolution during the 1992 and 1999 floods.

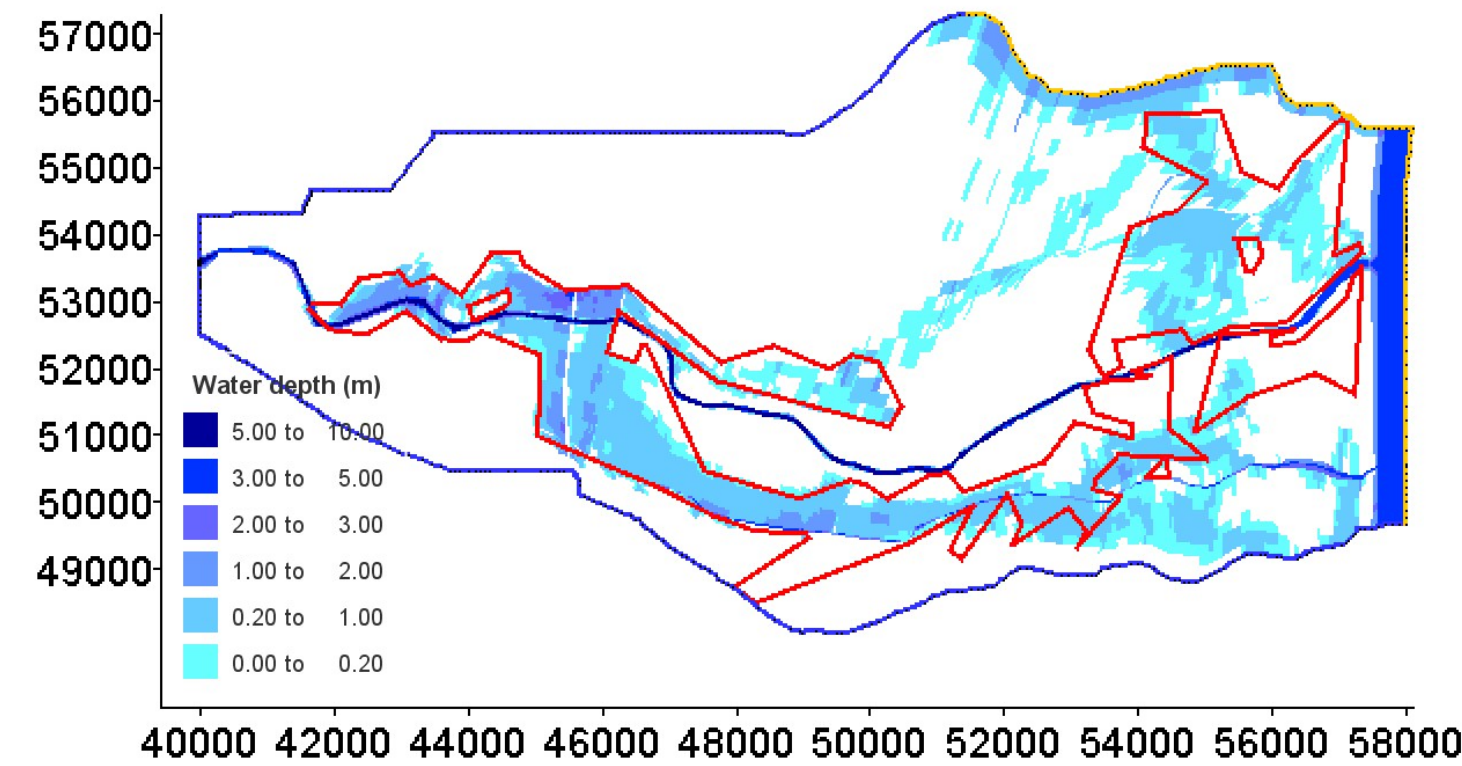

Figure 4. Calculated flooded area during the 1999 flood with 2D Rubar20TS model (peak water depths in meters; red line shows observed limit of flood, $x$ and $y$ coordinates in meters). 


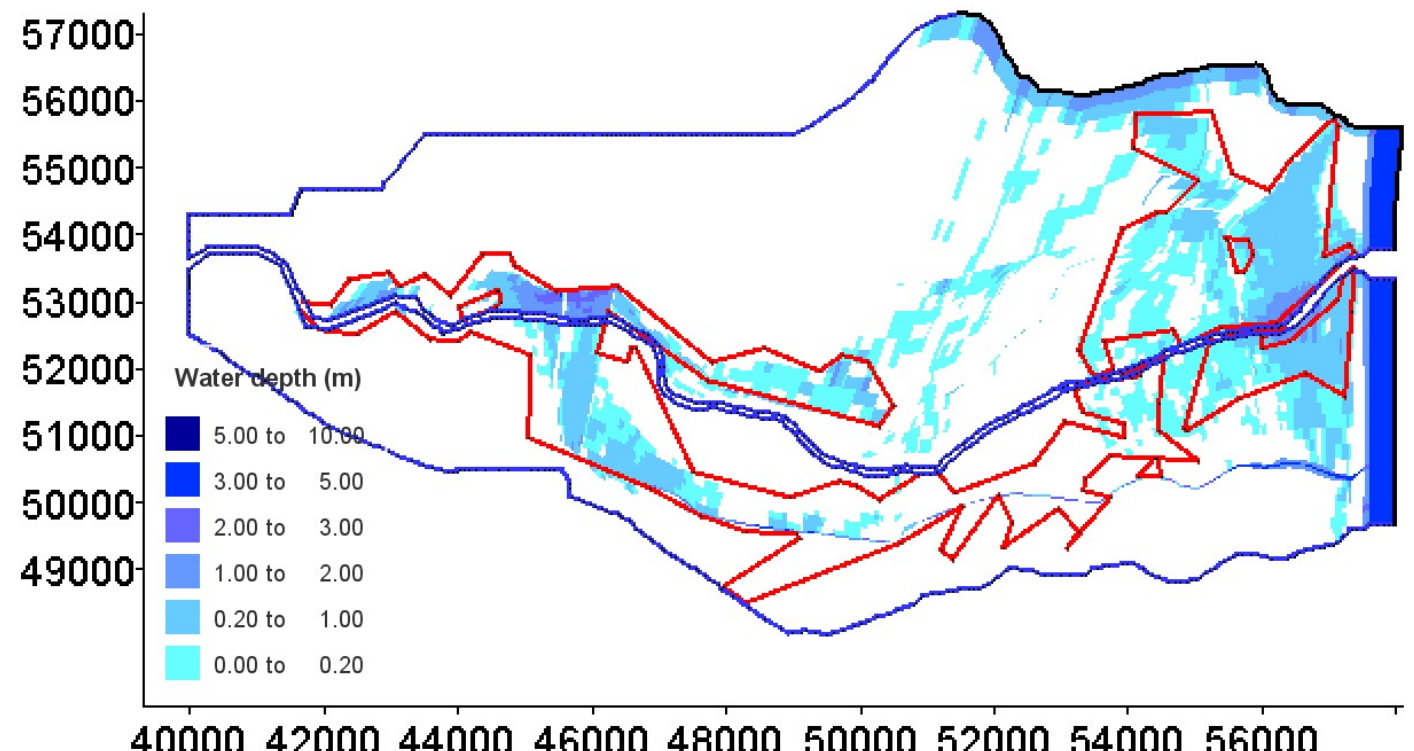

Figure 5. Calculated flooded area during the 1999 flood with the coupled 1D/2D model (peak water depths in meters; red line shows observed limit of flood, $x$ and $y$ coordinates in meters).
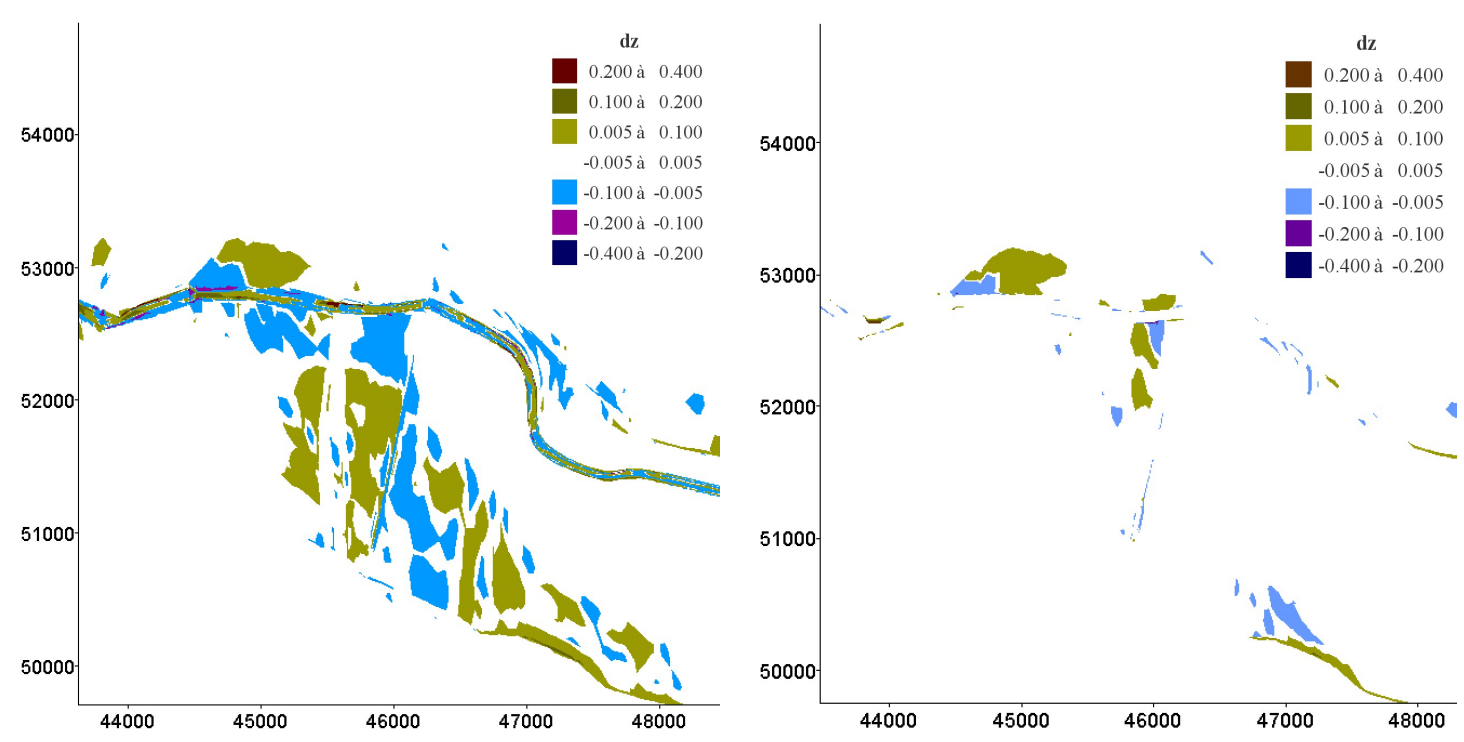

Figure 6. Zoom at erosion and sedimentation areas in the upstream part of reach between levees for the 1999 flood with the 2D model Rubar20TS (left) and with the 1D/2D coupled model (right) $(d z=$ deposit thickness in meters, $x$ and $y$ coordinates in meters).

Figure 6 shows the erosion and sedimentation areas in the floodplain at the upstream part of the reach between levees calculated with the 2D model Rubar20TS and the 1D/2D coupled model. The same processes can be found in the two models, with larger bed evolutions presented by the 2D model that inundates more. 


\section{CONCLUSION}

The main processes are quite similar in the two models and the slightly better representation of the 1999-flooded area using the 2-D model is likely to come from the calibration performed on the 2-D model (parameters being extended to the coupled model). Deposits and erosions in the floodplain are quite similar in the two models although the 2-D model that inundates more consequently changes the bed elevation more. The trend and the amplitude of bed elevation changes are quite different in the main channel for the two models; although the 1-D and the 2-D models use the same parameters, the location of the sediment balance (one cross section in 1-D, one cell in 2-D) results in different behaviours of the main channel while the differences in the flood plain morphological changes only come from the location and intensity of overflow. Because the available data are not enough accurate and because the model results depend strongly on sediment parameters, one cannot decide which model provides the more relevant results. However, the time calculation is reduced by about $50 \%$ using the coupled model, which thus represents the more practical tool.

\section{ACKNOWLEDGEMENTS}

The PROFAS B + program for the scholarship (Algerian-French cooperation) funded the stay of first author at INRAE.

\section{REFERENCES}

Camenen, B., Béraud, C., Le Coz, J. \& Paquier, A. 2018. 1D morphodynamic modelling using a simplified grain size description. Journal of Hydraulic Research 56(2): 168-180.

EL Kadi, K.\& Paquier, A. 2009. One-dimensional numerical modeling of sediment transport and bed deformation in open channels. Water Resources Research 45: W05404.

El Kadi, K., Paquier, A. \& Mignot, E. 2009. Modelling flash flood propagation in urban areas using a twodimensional numerical model. Natural Hazards 50: 433-460.

Exner, F. M. 1925. Über die wechselwirkungzwischenwasser und geschiebe in flüssen (On the interaction between water and sediment in rivers). Acad. Wissenscaften Wien Math. Naturwiss, Abt. 2a134: 165180.

Khodashenas, S. R. \& Paquier, A. 1999. A geometrical method for computing the distribution of boundary shear stress across irregular straight open channels, Journal of Hydraulic Research 37: 381-388.

Meyer-Peter, E. \& Müller, R. 1948. Formulas for bed load transport, Proc. 2nd Meeting IAHR: 39-64. Stockholm: IAHR.

Paquier, A. 2019. A method for coupling 1D and 2D models used to simulate floods and its application to the Niger inner delta. Modeling Hydrodynamics for Water Resources - MODWATER 2019. Zaragoza: University of Zaragoza.

Serrat, P. 2000. Genesis and dynamics of a Mediterranean river system: the Agly basin (France). PhD thesis. Perpignan: Perpignan \& Blaise Pascal Universities. 